\title{
Impairment of The Baroreflex Control of Human Respiratory RESISTANCE WITH AgE
}

\author{
M. Tafil-Klawe1', J. J. Klawe², P. Zalewski², A. Lewandowski ${ }^{3}$ \\ ${ }^{1}$ Department of Human Physiology, Medical Faculty and ${ }^{2}$ Department of Hygiene and Epidemiology, Faculty of Health Sciences and \\ ${ }^{3}$ Department of Basis of Physical Education, Faculty of Health Sciences, Collegium Medicum in Bydgoszcz, Nicolaus Copernicus University \\ in Torun, Poland
}

\begin{abstract}
Background: The mechanism responsible for the central baroreflex resetting with age are an area of limited knowledge. We previously demonstrated that in subjects aged above 50 the airway resistance did not change in response to baroreceptor activation, whereas in younger volunteers the airway resistance significantly decreased.

Objective: The aim of the present study was to evaluate the effect of carotid baroreceptor inactivation on the reflex change of respiratory resistance, in the course of aging.

Material and methods: 80 healthy men, divided in four groups: aged 20-30 (Group I), 31-40 (Group II), 41-50 (Group III), and 51-60 (Group IV) were included in the study. The selective inactivation of carotid baroreceptors was induced by generating a positive pressure of $40 \mathrm{mmHg}$ for $5 \mathrm{~s}$ in two capsules placed bilaterally on the neck over the bifurcation of the carotid arteries. The oscillatory method (Siregnost FD5, Siemens) was used to measure continuously respiratory resistance.

Results: Inactivation of carotid baroreceptors produced a short increase in respiratory resistance by 0.38 $\pm 0.01 \mathrm{SE} \mathrm{mbar} / 1 / \mathrm{s}$, i.e., $21.7 \%$ above the resting level in Group I and by $0.25 \pm 0.01 \mathrm{mbar} / \mathrm{l} / \mathrm{s}$ in Group II. In the two older groups (III and IV) respiratory resistance did not change in response to baroreceptors inactivation.

Conclusions: In humans aged above 40 , carotid baroreceptors do not contribute to bronchodilator tone, which causes imbalance between the activities of upper airway and chest wall inspiratory muscles leading to a collapsing effect on the upper airway.
\end{abstract}

Key words: aging, airway resistance, baroreflex, upper airway

\section{INTRODUCTION}

Numerous studies in humans have demonstrated impairment of baroreflex control of heart rate with advancing age $[1,2,3]$. Studies in animal models showed decreased baroreceptor sensitivity by direct electrophysiological recordings of baroreceptor discharges [4]. Reduced reflex response during equivalent levels of baroreceptor input, showed in other studies, indi- cates a central defect, demonstrated in animal studies free of atherosclerosis and hypertension $[4,5,6]$. The mechanisms responsible for central baroreflex resetting with age probably involve enhanced interaction between the hypothalamic centers and the solitary tract nucleus, and an exaggerated central adaptation to baroreflex input [7,8]. Our previous study showed that selective carotid baroreceptors activation decreases airway resistance in humans $20-40$ years old, whereas this response did not occur in older subjects $[9,10]$. The aim of the present study was to evaluate the effect of carotid baroreceptor inactivation on the reflex change of respiratory resistance in the course of aging.

\section{MATERIAL AND METHODS}

The study was approved by a local Ethics Committee and was performed in accordance with the Helsinki Declaration for Human Research. Eighty male subjects were enrolled into the study. Table 1 demonstrates four age-differentiated groups of subjects. All subjects were healthy, normotensive, and non-smokers. Subjects with a history of snoring or exceeding $150 \%$ of ideal body weight were excluded from the study in order to avoid the effects of snoring or obesity on the cardiovascular system. All experiments were performed at rest in the seated recumbent position.

\section{INACTIVATION OF CAROTID BARORECEPTORS}

In order to inactivate carotid baroreceptors a twoneck-chamber method was applied. Selective inactivation of carotid baroreceptors was induced by generating a positive pressure of $40 \mathrm{mmHg}$ for $5 \mathrm{~s}$ in two capsules placed bilaterally on the neck over the bifurcation of the carotid arteries. The stimuli were applied $250 \mathrm{~ms}$ after the R-wave during the expiratory phase of breathing. The maximal rate of air pressure increase was $300 \mathrm{mmHg}$ per second. The following variables were recorded continuously:

- R-R intervals, measured from ECG;

- Respiratory phase and the rate of breathing by means of a termistor placed at the nose orifice;

- Air pressure in the neck chambers. 
- Average R-R interval was calculated from $10 \mathrm{~s}$ of recording preceding the onset of stimulus and is referred to as the baseline. The cardiac baroreflex response was expressed as a gain of heart response (GHR) and was calculated as the peak value of the $\mathrm{R}-\mathrm{R}$ shortening during the $5 \mathrm{~s}$ after the onset of stimulus, compared with the baseline level, divided by the neck pressure change.

\section{MeAsurement of Respiratory Resistance}

The oscillatory method (Siregnost FD5, Siemens) was used to measure continuously respiratory resistance, as described in detail elsewhere [11]. This technique is well suited for the measurement of dynamic changes of respiratory resistance as it requires little compliance from patients.

\section{RESULTS}

Table 1 demonstrates the summarized data. The calculated mean cardiac response following baroreceptors activation did not differ between Group I and Group II. However, the two older groups of volunteers demonstrated a reduced reflex heart rate response to baroreceptors inactivation $(\mathrm{P}<0.01)$. The oldest subjects studied (Group IV), aged 51-60 years, showed a blunted response compared with the other groups $(\mathrm{P}<0.01)$.

All subjects from Group I and Group II demonstrated an increase in respiratory resistance in response to carotid baroreceptors inactivation. However, this reaction was significantly reduced in the subjects aged $31-40(\mathrm{P}<0.01)$. In the two older groups of subjects, respiratory resistance did not change in response to baroreceptors inactivation.

\section{DISCUSSION}

Baroreceptors sensitivity, considered as a reflex shortening of R-R interval in response to baroreceptors inactivation, is strongly age-related. Our previous study showed a reduction of cardiac response to baroreceptors activation in the course of aging [10]. Impairment of the baroreflex may contribute to increased sympathetic activity and the later development of hypertension in the elderly, but also to the orthostatic intolerance. Increases in blood pressure increase the severity of upper airway airflow obstruction by increasing pha- ryngeal collapsibility [12]. Thus, baroreceptors have been implicated in the regulation of upper airway patency. It is known that baroreceptor input may influence respiratory output: pulsatile baroreceptor input may partially entrain respiratory rhythm $[13,14]$ and modulate respiratory neuronal activity $[15,16]$. When baroreceptor input is very high, as might happen during extreme exertion or during periods of very low ventilatory drive, such as deep sleep, it appears that baroreceptors may modulate respiratory rhythmogenesis [17]. The present study showed another respiratory component of the baroreflex in humans: inactivation of baroreceptors produces an increase in respiratory resistance. This reaction disappears in subjects over 40 years old. In younger subjects, tonic drive from carotid baroreceptors might influence respiratory resistance, resulting in a decrease in inspiratory effort. A decrease in respiratory effort means a decrease in activities of the diaphragm and chest wall inspiratory muscles. Impairment of this component of the baroreflex, occurring in the course of aging, might evoke an imbalance between the activities of upper airway and other inspiratory muscles, facilitating the collapsibility of the upper airway [18]. Thus, physiological process of aging and a reduction in the respiratory baroreflex function may promote instability of the upper airway.

In conclusion, impairment of the baroreflex control of respiratory resistance in the course of aging might be one possible pathogenic mechanism of obstructive sleep apnea in subjects older than 40 years.

Conflicts of interest: No conflicts of interest were reported by the authors in relation to this article.

\section{REFERENCES}

[1] Gribbin B, Pickering TG, Sleight P, Peto R. Effect of age and high blood pressure on baroreflex sensitivity in man. Circ Res 1971; 29: 424-31.

[2] Hajduczok G, Chapleau MW, Johnson SL, Abboud FM. Increase in sympathetic activity with age. I. Role of impairment of arterial baroreflexes. Am J Physiol 260: H1113-20.

[3] Ebert TJ, Morgan BJ, Barney JA, Denahan T, Smith JJ. Effects of aging on baroreflex regulation of sympathetic activity in humans. Am J Physiol 1992; 263: H798-803.

[4] Chapleau MW, Abboud FM. Mechanisms of adaptation and resetting of the baroreceptor reflex. In: Cardiovascular reflex control in health and disease. R. Hainsworth and A. L. Mark (eds), Saunders Company, 1993, pp. 16593.

Table 1. Respiratory resistance and hart rate changes (GHR) in response to carotid baroreceptors inactivation in age-differentiated volunteers.

\begin{tabular}{ccccc}
\hline Groups & I & II & III & IV \\
\hline Age (yr; range/mean \pm SE) & $20-30$ & $31-40$ & $41-50$ & $51-60$ \\
& $25.4 \pm 0.6$ & $33.7 \pm 0.8$ & $45.2 \pm 0.9$ & $56.1 \pm 0.9$ \\
GHR (mean \pm SE) & $-4.13 \pm 0.03$ & $-3.75 \pm 0.03$ & $-3.00 \pm 0.03$ & $-2.34 \pm 0.03$ \\
& & & No change & No change \\
Respiratory resistance change (mbar/l/s) (mean \pm SE) & Increase & Increase & & \\
\end{tabular}


[5] Ma S, Chapleau MW, Abboud FM. Defekt In central mediation of the baroreflex with aging. FASEB J 1992; 6: A951 (abstract).

[6] Tanabe S, Bunag RD. Age-related central and baroreceptor impairment in female Sprague-Dawley rats. Am J Physiol 1989; 256: H1399-406.

[7] Tanabe S, Bunag RD. Aging escalates baroreceptor reflex suppression by the posterior hypothalamus in rats. Hypertension 1991; 17: 80-90.

[8] Hajduczok G, Chapleau MW, Abboud FM. Rapid adaptation of central pathways explains the suppressed baroreflex with aging. Neurobiol Aging 1991; 12: 601-4.

[9] Klawe JJ, Hildebrandt G, Przybylski J, Tafil-Klawe M. Reflex effects of stimulating arterial baroreceptors and other cervical mechanoreceptors by neck suction in humans. Med Sci Monit 1999; 5: 609-14.

[10] Klawe JJ, Szajnach W, Tafil-Klawe M, Grote L, Peter JH, Smietanowski M. Age-dependent carotid baroreceptor control of human airway resistance. Med Sci Monit 1999; 5: 615-17.

[11] Von Korn V. Die Bestimmung des Atemwiderstandes mit dem oszillatorischen Messprinzip, Siregnost FD5, Dustri Verlag, 1979, pp. 16-40.

[12] Mayor AH, Schwartz AR, Rowley JA. Willey SJ, Gillespies MB, Smith PL, Robotham JL. Effect of blood pressure changes on air flow dynamics in the upper airway in the decerebrate cat. Anesthesiology 1996; 84: 128-34.

[13] Tzeng YC, Larsen PD, Galletly DC. Cardioventilatory coupling in resting human subjects. Exp Physiol 2003; 88: 775-82.
[14] Tzeng YC, Larsen PD, Galletly DC. Mechanism of cardioventilatory coupling: insights from cardiac pacing, vagotomy, and sinoaortic denervation in the anesthetized rats. Am J Physiol 2007; 292: H1967-77.

[15] Dick TE, Morris KF. Quantitative analysis of cardiovascular modulation in respiratory neural activity. J Physiol 2004; 556: 959-70.

[16] Dick TE, Shannon R, Lindsey BG, Nuding SC, Segers LS, Baekey DM, Morris KF. Arterial pulse modulated activity is expressed in respiratory neural output. J Appl Physiol 2004; 99: 691-98.

[17] McMullan S, Dick TE, Farnham MMJ, Pilowsky P. Effects of baroreceptor activation of respiratory variability in rat: Respir Physiol Neurobiol 2009; 166: 80-6.

[18] Parisi RA, Neubauer JA, Frank MM. Correlation between genioglossal and diaphragmatic responses to hypercapnia during sleep. Am Rev Respir Dis 1987; 135: 378-82.

Address for correspondence:

Prof. M. Tafil-Klawe

Department of Human Physiology

Medical Faculty

Collegium Medicum

Karlowicza 24 St.

85-092 Bydgoszcz

Poland

Phone: +48604 547374

E-mail: Femcia@op.pl 